\title{
Atenção à Saúde do Idoso: o pensar e o fazer Políticas Públicas*
}

Attention to the Elder's Health: thinking and doing Public

Policies

Atención a la Salud del Anciano: el pensar y hacer

Políticas Públicas

Susane Fátima Ferreira de Castro Francisco Oliveira Barros Júnior

RESUMO: Este trabalho objetivou analisar como as ações voltadas para a saúde do idoso vêm sendo pensadas e executadas. A construção dos dados foi guiada por um roteiro de entrevista semiestruturado e a análise, pela problematização dos discursos. Verificou-se que as ações direcionadas para a saúde do idoso são gestadas e materializadas sob a égide da fragmentação entre o pensar e o fazer, não visualizando as velhices em sua heterogeneidade.

Palavras-chave: Saúde do Idoso; Políticas Públicas; Integralidade em Saúde.

ABSTRACT: The goal was to analyze how the actions towards the health of the elder are planned and executed.The construction of the data was guided by a semi-structured interview questionnaire and the analysis for the discussion of the speeches.The actions towards the health of the elderly are gestated and materialized under the aegis of the fragmentation between the thinking and the action, not seeing the old age in its heterogeneity.

Keywords: Elder's Health; Public Policy; Health Integrality.

\footnotetext{
* Este artigo resulta de uma sua versão preliminar, em forma de Comunicação de similar título, apresentada pelos mesmos autores na VII Jornada Internacional de Políticas Públicas, realizada de 25-28/agosto/2015, na UFMA, Universidade Federal do Maranhão, e publicada em: http://www.joinpp.ufma.br/jornadas/joinpp2015/pdfs/eixo6/atencao-a-saude-do-idoso-o-pensar-e-o-fazer-politicas-publicas.pdf.
} 
RESUMEN: El objetivo fue analizar cómo se planifican y ejecutan las acciones hacia la salud del anciano. La construcción de los datos fue guiada por un cuestionario de entrevista semiestructurada y el análisis para la discusión de los discursos. Las acciones hacia la salud De los ancianos se gestan y se materializan bajo la égida de la fragmentación entre el pensamiento y la acción, no viendo la vejez en su heterogeneidad.

Palabras clave: Salud del Anciano; Política Pública; Integridad de la Salud.

\section{Algumas Considerações Iniciais}

O envelhecimento cada vez mais estendido é uma realidade entre nós, um cenário que vem se materializando nos múltiplos espaços sociais, e com contornos de vitória, haja vista que se vivencia um aumento significativo da expectativa de vida das pessoas, algo que é fruto de um esforço no qual a saúde ocupa posição central, com melhoria de indicadores que possibilitaram a redução da taxa de mortalidade infantil no Brasil, aumentando a quantidade de anos vividos.

Conceitualmente, o processo de envelhecimento é definido a partir do conjunto de condições biológica, social, cognitiva, econômica, funcional e cronológica. Biologicamente, o envelhecimento se inicia no momento em que a pessoa nasce; socialmente, a velhice varia de acordo com o momento histórico e cultural; intelectualmente, diz-se que uma pessoa está velha quando suas faculdades mentais começam a falhar, apresentando problemas de atenção, memória, concentração e orientação, dentre outros; funcionalmente, quando perde sua independência para realizar as atividades da vida diária; e, cronologicamente, a pessoa é idosa quando faz 60 anos ou 65 anos (Silva, 2009).

De acordo com Andrade, Silva, e Santos (2010), a população de pessoas acima de 60 anos, na sociedade brasileira, está em franco crescimento, associando-se a esse fenômeno os rápidos avanços da medicina e da tecnologia que concorrem para favorecer o envelhecimento de forma mais saudável e com melhor qualidade de vida. Laroque, et al. (2011), ainda na esteira das razões que convergem para o envelhecimento populacional, expõem que o aumento dessa longevidade, tributário ao arsenal tecnológico de que dispõe a ciência, devido ao seu crescente progresso, contribui, desse modo, para o aumento significativo da população longeva. 
Segundo Freitas, Neri, Cançado, Doll, e Gorzoni (2006), o envelhecimento populacional responde por um fenômeno mundial incontestável e ocorre tanto em países considerados desenvolvidos como naqueles ditos em desenvolvimento. O Brasil apresenta, por sua vez, um dos mais agudos processos de envelhecimento populacional, sendo este resultado das mudanças de alguns indicadores de saúde, em especial a queda da fecundidade e da mortalidade e o aumento da esperança de vida.

Atualmente, no Brasil, é evidente o envelhecimento da população, com uma perspectiva de aumento para 32 milhões em 2025, devido à diminuição nos índices de natalidade e fecundidade nos últimos anos, e do aumento da longevidade, favorecidos pelos avanços tecnológicos na área da saúde (Schimidt, \& Silva, 2012). O Instituto Brasileiro de Geografia e Estatística, IBGE evidencia essa realidade, ao relatar que:

O segmento populacional que mais aumenta na população brasileira é o de idosos, com taxas de crescimento de mais de $4 \%$ ao ano no período de 2012 a 2022. A população com 60 anos ou mais de idade passa de 14,2 milhões, em 2000, para 19,6 milhões, em 2010, devendo atingir 41,5 milhões, em 2030, e 73,5 milhões, em 2060. Espera-se, para os próximos 10 anos, um incremento médio de mais de 1,0 milhão de idosos anualmente. Essa situação de envelhecimento populacional é consequência, primeiramente, da rápida e contínua queda da fecundidade no país, além de ser também influenciada pela queda da mortalidade em todas as idades (IBGE, 2015, p. 146).

No estado brasileiro do Piauí, conforme Alencar, e Carvalho (2009), a proporção de pessoas idosas está crescendo progressivamente de forma rápida e intensa, passando de $7 \%$, em 1992, para 8,2\%, em 1999, destacando-se a maior concentração na faixa etária entre sessenta e sessenta e nove anos, com predominância do sexo feminino. As estimativas do Censo Demográfico de 2004 para a população total do município de Teresina, PI corresponderam a 715.360 habitantes, dos quais 44.437 são pessoas com sessenta anos ou mais. Dados do IBGE mostram que, em 2002, o Piauí possuía uma população de 254.000 pessoas idosas. Esse número vem apresentando uma ascensão significativa no Estado mencionado, de modo que, no ano de 2008, a quantidade de idosos respondia por 349.000 indivíduos com 60 anos ou mais. Projeções para 2022 colocam o Piauí com 16,6\% da sua população total constituída pelo segmento idoso (IBGE, 2015). 
Em termos biológicos, afirmam Camacho, e Coelho (2010), o envelhecimento é um processo natural, progressivo, e universal, que compreende uma redução da capacidade funcional da pessoa idosa e se caracteriza por uma maior vulnerabilidade às doenças, de uma maneira geral. Entretanto, entende-se tal processo a partir de uma ótica multidimensional, de modo que, para além de influenciar mudanças biológicas, desencadeia alterações sociais, culturais e emocionais. Alterações estas que desenham um panorama que abriga uma variedade de formas de envelhecer, atreladas às condições de vida dessas pessoas que, na realidade brasileira, são permanentemente atravessadas pelas desigualdades sociais, fomentando barreiras para a concretização da cidadania do idoso.

A heterogeneidade entre os idosos suscita a necessidade da existência de modelos de atenção diversos. Nos termos de Omelczuk, e Monteiro (2014), “ao simples fato demográfico do envelhecimento populacional, agregam-se inúmeras urgências e desafios, bem como transformações políticas, culturais, psicossociais e econômicas", que não deixam de ser fundantes e fomentadores a novos modos de conceber e enfrentar o envelhecimento.

Isso vai moldando implicações para as políticas públicas que precisam articular novas concepções de assistência à saúde da população idosa, passíveis de englobar as diferentes condições desses indivíduos, respeitando suas características especiais e peculiares. Os clássicos modelos de promoção, prevenção, assistência e reabilitação não podem ser mecanicamente transportados para grupos de pessoas idosas, sem que algumas adaptações importantes e significativas sejam realizadas (Berlezi, et al., 2011).

Com essa nova realidade no país, que acontece de forma rápida e progressiva, elucidam Oliveira, e Tavares (2010), a situação dos idosos exige capacitação para atender as especificidades dessa faixa etária por parte dos profissionais de saúde, melhorando a assistência prestada, sendo necessária a implantação de inovações para promover uma assistência mais humana e integral à saúde da pessoa idosa, bem como conhecer melhor esse grupo para poder promover um envelhecimento saudável e ativo.

Dentro desse cenário, políticas públicas voltadas para os idosos foram elaboradas com o propósito de contribuir para que um maior número de pessoas alcance, não somente um maior número de anos vividos, mas um envelhecimento bem-sucedido. Dentre essas políticas, ressaltam-se o Estatuto do Idoso e a Política Nacional de Saúde da Pessoa Idosa, PNSPI. 
O Estatuto do Idoso é a forma legal criada para regulamentar os direitos fundamentais da pessoa idosa e amparar o direito de atenção integral à saúde do idoso (Ciosak, et al., 2011). A PNSPI, por sua vez, tem como objetivo principal recuperar, manter, promover a autonomia e a independência das pessoas idosas por meio do desenvolvimento de ações de saúde coletivas e individuais em consonância com os princípios e diretrizes do Sistema Único de Saúde, SUS (Lima, \& Tocantins, 2009).

Verifica-se que as políticas priorizam os direitos que o idoso tem para garantir uma velhice mais digna. No entanto, esses direitos devem ser materializados na assistência prestada ao idoso e refletir em ganhos reais no seu cotidiano, exigindo-se que o profissional de saúde veja o idoso com um novo olhar, um olhar que vai além da sua aparência ou das patologias consideradas próprias da velhice. A assistência prestada à pessoa idosa precisa ser delineada de maneira multidimensional e integralizada, para que haja um entendimento das particularidades que envolvem essa faixa etária.

Diante do exposto, este estudo traz como objetivo analisar como as ações voltadas para a saúde do idoso são planejadas e executadas no município de Teresina, PI, e sob quais concepções de ser idoso, a partir do entendimento de que as pessoas pensam e agem ancorados nos referenciais que possuem. Ir ao encontro desses referenciais dos gestores e profissionais na área da saúde do idoso abre portas para a compreensão das lacunas e fragilidades presentes nos caminhos de transposição das políticas públicas do contexto da produção para o contexto da prática.

\section{Percurso Metodológico}

Utilizou-se uma metodologia analítica, de caráter exploratório, com abordagem qualitativa, visto que esta explica, nas palavras de Minayo, e Gomes (2012), os meandros das relações consideradas essência e resultado da atividade humana criadora, afetiva e racional que pode ser apreendida no cotidiano, por meio da vivência e da explicação. Ademais, pode responder às questões particulares, em um espaço mais profundo das relações, considerandose como participantes do estudo pessoas pertencentes a um determinado grupo, com suas crenças, concepções, valores, significados e práticas individuais. 
A construção dos dados foi realizada no período de maio a setembro de 2014 e teve como cenários de pesquisa a Fundação Municipal de Saúde, FMS, órgão executor de vigilância e atenção à saúde, e os serviços de saúde, prioritariamente, unidades básicas de saúde e um ambulatório especializado.

Os participantes do estudo foram quatro gestores que atuam, direta ou indiretamente, na área da saúde do idoso e 10 profissionais de saúde, quantidade definida pela saturação dos discursos produzidos. Esses interlocutores foram selecionados de acordo com os seguintes critérios de inclusão: profissionais atuantes nas áreas de interesse da pesquisa, na gestão e na assistência, em vários componentes da rede de saúde, de ambos os sexos, e que aceitaram participar voluntariamente do estudo.

Para a construção dos dados, utilizou-se um roteiro de entrevista semiestruturada, aplicado pela própria pesquisadora nos cenários já descritos, em locais reservados e preparados, a fim de preservar a privacidade durante os relatos dos interlocutores, sendo previamente agendados. As entrevistas foram gravadas e, em seguida, transcritas, sempre garantindo o anonimato dos participantes e, para isso, os interlocutores foram identificados por nome de pedras preciosas. Foram, ainda, realizadas, mediante a assinatura do Termo de Consentimento Livre e Esclarecido, de acordo com as recomendações da Resolução 466/2012 do Conselho Nacional de Saúde.

A análise construída dos dados foi guiada pela produção de sentidos, uma abordagem teórico-metodológica para exame minucioso das práticas discursivas. Conforme Spink, e Medrado (2000), o sentido é uma construção social, um empreendimento coletivo, mais precisamente interativo, por meio do qual as pessoas, na dinâmica das relações historicamente datadas e culturalmente localizadas, constroem os termos a partir dos quais compreendem e lidam com situações e fenômenos a sua volta.

A ânsia estava em se deparar com os repertórios interpretativos dos múltiplos interlocutores da pesquisa, entendendo-se estes como unidades de construção das práticas discursivas, tendo por parâmetros os contextos em que essas práticas foram produzidas. A ambição em trabalhar as práticas discursivas em diferentes níveis buscou apreender a cristalização em discursos institucionalizados, as posições socialmente disponíveis e as estratégias utilizadas para se posicionar na interação. As práticas discursivas, portanto, implicaram necessariamente no uso de repertórios e posicionamentos identitários (Spink, \& Medrado, 2000). 
Como forma de atender aos preceitos éticos e legais de uma pesquisa realizada com seres humanos, a pesquisa foi submetida ao Comitê de Ética e Pesquisa do Hospital Getúlio Vargas, órgão colegiado, vinculado ao Comitê Nacional de Ética em Pesquisa, CONEP, para ser avaliada, e, somente mediante aprovação, deu-se início ao trabalho de campo propriamente dito.

\title{
Resultados e Discussão
}

De acordo com os dados analisados, a caracterização dos interlocutores, captada na parte inicial das entrevistas, revelou os seguintes achados: 10 participantes foram do sexo feminino e 04 do sexo masculino; o intervalo de faixa etária variou entre 27 e 55 anos; quanto à formação, 07 eram enfermeiros, 02 assistentes sociais, 01 nutricionista, 01 farmacêutico, 01 técnico de enfermagem, 01 médico e 01 psicólogo; o tempo de formação alternou entre 04 e 31 anos; e nenhum dos interlocutores recebeu qualquer capacitação na área de saúde do idoso.

Reconhecendo que os signos e sentidos trazidos por gestores e profissionais acerca do ser idoso modelam o pensar e o agir no contexto da atenção à saúde dessas pessoas, começouse a abrir espaços para esses discursos como forma de construir subsídios para alcançar como as ações destinadas às velhices são gestadas e como estas se materializam nos cenários dos serviços de saúde, com o propósito maior de compreender porque essas ações chegam até os idosos por vias fragmentantes e fragmentadas, não dando conta da multidimensionalidade do envelhecer.

A partir das falas dos interlocutores participantes da pesquisa, tanto aqueles que trabalham na FMS, os tidos gestores, como os profissionais de saúde, considerados os executores, foi possível extrair uma concepção de idoso muito atrelada a uma faixa etária, restringindo-se a alterações orgânicas e funcionais que acontecem com o avançar da idade, conforme expressam as falas que seguem:

\author{
“[...] aquela pessoa com mais de 65 anos [...]” (Opala) \\ "[...] que devido ao seu tempo de vida já tem alterações orgânicas e \\ funcionais [...]” (Opala) \\ “[...] se restringe a uma faixa etária [...]" (Esmeralda)
}


"[...] idoso é aquela pessoa que completou 60 anos, né?, completou 60 anos é considerado idoso, que é a faixa etária que está, é, considerada idoso." (Jade)

"Na minha concepção, juro por Deus que é uma pessoa acima de 65 anos, na minha cabeça é o que vem, acima de 65 anos é uma pessoa idosa." (Topázio)

“Acima de 60 anos." (Rubi)

"Idoso é uma pessoa experiente, que tem acima de 60 anos, como o Estatuto prevê [...]" (Ônix)

"[...] uma, uma alteração na... no padrão físico, mental, que há um comprometimento [...]” (Turquesa)

"Bom, é... do ponto de vista objetivo, a gente segue aqueles parâmetros é, é, é, por definição, né?, que seria aquele paciente acima de 60 anos de idade [...]" (Granada)

“O idoso, para mim, é uma faixa etária [...]” (Malaquita)

"[...] é uma pessoa que conseguiu atingir uma idade, uma determinada idade dentro daquilo que o Estatuto do Idoso preconiza dos 60 anos." (Pedra da Lua)

A velhice é enquadrada, certifica Mucida (2006), em um discurso que a associa a diferentes fatores constitucionais, herdados e adquiridos durante o envelhecimento. Observase que a velhice é definida sob o âmbito das perdas, das reduções de memória, do juízo crítico, com diminuição da capacidade intelectual e do raciocínio lógico, afetando, assim, a vida social e afetiva do idoso. Interessa a esse discurso o corpo tomado como organismo, marcado pelo determinismo biológico. Nas palavras de Debert (2011), encara-se a idade como um dado da natureza e um fator explicativo dos comportamentos humanos, além de se conceber o curso da vida como uma sequência unilinear de etapas evolutivas. Existe uma idade normal, um corpo normal, um comportamento normal, reforça Elias (2001). E o que foge desse normal é considerado um desvio social.

Na nossa sociedade, a idade cronológica - que é um sistema de datação ausente em muitas outras sociedades - é assim um mecanismo fundamental na organização social, porque determina em outras coisas a maioridade civil, o início da vida escolar, a entrada e a saída no mercado de trabalho. 
A velhice, como as categorias etárias, étnicas, raciais ou de gênero, é uma forma de segmentar e classificar uma população, mas também de construir uma hierarquia entre diferentes segmentos assim construídos (Debert, 2011, p. 547).

É fato que o passar dos anos vai desenhando, na dimensão biológica das pessoas, mudanças que convergem para novas formas e funções corporais, tidas como características comuns na velhice; esse processo, porém, não acontece da mesma maneira, ritmo e intensidade em todos os indivíduos com mais de sessenta anos, imprimindo nas experiências destes, percepções e respostas diferentes no que tange às mudanças que vão ocorrendo ao longo dos anos.

$\mathrm{Na}$ velhice, muitas perdas corporais podem escancarar-se sem nenhuma promessa de aquisição; pequenas e continuadas mudanças podem se inscrever a partir da meia-idade, de modo que cabelos brancos, rugas, elasticidade da pele e, pouco a pouco, outras alterações indicam ao sujeito que seu corpo não é mais o mesmo, principalmente no tocante às belas formas. Embora essas mudanças não reflitam em doenças, elas podem ser interpretadas como tais em uma tentativa de denegação do real da imagem (Mucida, 2006).

O envelhecimento, em termos gerais, é definido como um processo que acompanha o organismo do nascimento à morte. A velhice é um momento específico dentro desse processo marcado pelo agudizamento de diferentes reduções e modificações de diversas funções, bem como determinadas alterações celulares, não implicando, todavia, em um acúmulo de doenças. Dentro do conhecimento teórico que cerca a velhice e o envelhecimento, dois conceitos são recorrentes: senescência e senilidade. O primeiro é definido como um processo fisiológico inelutável do organismo que acarreta modificações precisas, associadas a uma redução de todas as funções sem provocar doenças. A senilidade, por sua vez, refere-se às patologias do envelhecimento, de modo que há mudanças precisas que se agudizam a partir de determinada idade, variável para cada organismo, e que podem ser expressas sob diferentes maneiras nas funções respiratórias, circulatórias, pulmonares etc., bem como na imagem, com rugas, cabelos brancos, menor elasticidade da pele, flacidez, entre outras (Mucida, 2006).

Nesse contexto, podemos nos questionar se envelhecer seria uma experiência positiva ou negativa? Na verdade, um processo com expressão na temporalidade da pessoa, aderindo à sua história de vida, de maneira que envelhecemos como vivemos, nem melhor, nem pior. 
Trata-se de um equilíbrio entre a aquisição, aspecto positivo, e as perdas, consideradas muitas vezes de caráter negativo, embora a perda nem sempre represente um término; muitas vezes engendra uma aquisição (Marrano, \& Simões, 2006).

Isso nos leva a reconhecer e defender que a velhice é fortemente atravessada pela heterogeneidade. Lima, Arcieri, Garbin, e Moimaz (2010) asseveram acerca de uma ideia que carregamos como dorsal na nossa prática, a existência de velhices. As velhices das capas de revista, da mídia, da imagem construída pelo mercado capitalista, o que não nos autoriza a descartar algumas realidades marcadas pelo medo, depressão, falta de assistência, falta de lazer, abandono, desinformação e preconceitos. Nesse sentido, o cuidado ao idoso precisa considerar essa diversidade de formas de envelhecer.

Na atualidade, alerta Mucida (2006), o idoso encontra diferentes formas de se deparar com o desamparo. Sua história não encontra lugar diante das "nov-idades" do mercado; sua imagem não pode acolher como antes as maquilagens, mesmo com o mercado das próteses e das cirurgias plásticas, tendo em vista que o limite persiste. $\mathrm{O}$ temor à perda de amor torna-se real dada a fragilidade corporal que não responde, como antes, aos imperativos de força, beleza e agilidade. Os caminhos abertos pela cultura à inscrição e atualização de sua história tornam-se também mais restritos. É flagrante, no mundo atual, o desrespeito ao idoso concernente à sua fala, à sua marcha sempre mais lenta, sempre em descompasso com um mundo que gira ao redor de outros imperativos acima mencionados. De acordo com Elias (2001), a sensação "talvez eu fique velho um dia" (grifos do autor) pode estar inteiramente ausente. Tudo o que sobra é o gozo espontâneo de nossa própria superioridade, e do poder dos jovens em relação aos velhos.

Essa polifonia de discursos sobre o envelhecimento invade os espaços dos serviços de saúde na forma de múltiplas subjetividades, latentes ou manifestadas, trazidas por cada indivíduo na expressão das suas necessidades, quando buscam por atendimento; entretanto não ganham corpo e espaço, tendo em vista as concepções já existentes e materializadas na prática dos profissionais sobre o idoso, ancoradas no plano físico, das doenças e incapacidades, em razão de uma faixa etária específica. Nesse propósito, ao representarem a velhice pela lente das mudanças, sofridas ao longo do tempo, direcionam suas ações junto aos idosos para evitar ou controlar tais doenças e/ou condições limitantes, fazendo uso contínuo do mantra "ativo e saudável" (grifos nossos), reduzindo o entendimento desses conceitos à ausência de patologias e à capacidade de realizar as atividades de vida diária, configurando-se a tão exaltada independência. 
Além disso, contribui para uma leitura míope das políticas públicas destinadas à velhice, como a PNSPI, quando esta menciona o envelhecimento ativo e saudável como diretriz a ser trabalhada para a garantia do direito à saúde das pessoas idosas. Uma leitura que distorce e simplifica essas categorias à manutenção da independência do idoso dentro de uma perspectiva da capacidade de cuidar de si, apenas no atendimento de suas necessidades básicas, tal como ilustra o raciocínio da gestão municipal em saúde do idoso, não abrindo portas para uma reflexão do que realmente significam esses conceitos no cotidiano dos idosos e como eles são postos em estruturas sociais e econômicas tão diferentes e, sobretudo, desiguais.

"[..] a política pública, ela está aplicada a todas as pessoas acima de 60 anos, pra quê?;, qual é o objetivo dessas políticas?, que essas pessoas fiquem é, independentes, né?, que ela tem uma, uma, a gente já vem desde o início trabalhando para que as pessoas tenham qualidade de vida, pra quando ela chegar aos 60, elas continuarem uma vida, apesar de estar idoso, mas continuar ainda independente, né?, o máximo possível, que a gente sabe que o maior problema do idoso é quando ele fica dependente [...] [...] que as pessoa não tem tempo, hoje todo mundo trabalha muito, não pode cuidar, então quanto mais independente que ele for, é importante para ele, então o objetivo mesmo da política é tornar o idoso mais..., que ele tenha saúde... que torne ele independente, totalmente independente, né?" (Jade)

A Organização Mundial de Saúde (OMS) define o envelhecimento ativo como o processo da otimização das oportunidades de saúde, participação e segurança, com o objetivo de melhorar a qualidade de vida à medida que as pessoas ficam mais velhas. A palavra "ativo" (grifos do autor) refere-se à participação contínua nas questões sociais, econômicas, culturais, espirituais e civis, e não somente à capacidade de estar fisicamente ativo ou parte da força de trabalho. As pessoas mais velhas que se aposentam e aquelas que apresentam alguma doença ou vivem com alguma necessidade especial podem continuar a contribuir ativamente para seus familiares, comunidades e países. O objetivo do envelhecimento ativo é aumentar a expectativa de vida para todas as pessoas que estão envelhecendo, incluindo as que são frágeis e fisicamente incapacitadas (OMS, 2005). Essa visão restrita do ser ativo na velhice aparece na fala de um dos meus interlocutores, tal como expressa o fragmento de fala abaixo: 
“[... ] antes, com 60, 70, estava impossibilitado, estava afastado, aposentado, não estava na ativa. Hoje com 70 o pessoal tem... ativa, na ativa, 70, 75 anos, porque você sabe que até já mudou, né? Tá mudando aí as regras da aposentadoria, de tudo aí, porque hoje o Brasil já tá uma país de quê? De velhos. O censo tá aí.” (Malaquita)

Vislumbro, nesse afã, que o grande desafio localiza-se na capacidade de as ações direcionadas aos idosos darem conta dessa pluralidade de potencial de experiências. A PNSPI cumpre esse papel quando se fala em documento na dimensão escrita; afinal, uma das diretrizes presentes nesse texto legal é a atenção integral e integrada à saúde da pessoa idosa. Contudo, está sujeita às múltiplas interpretações de gestores e profissionais, o que vai moldando o contexto da prática da atenção à saúde do idoso.

A integralidade, aliás, é uma categoria dorsal aqui adotada para desvelar a problemática estudada, uma vez que, vestindo-se de uma polissemia característica, amalgama múltiplos sentidos, ancorada em um pensamento crítico, não reduzindo a realidade ao que existe. Dentro desse contexto prenhe de sentidos, Mattos (2001) nos coloca que a integralidade pode se corporificar nas propostas de respostas governamentais aos problemas de saúde e no modo de organizar e realizar as práticas, conferindo-se sustentação teórica para os discursos dos presentes interlocutores, e a consequente compreensão de algumas das questões postas como direcionadoras para a realização da pesquisa, sobretudo no que diz respeito a como as ações voltadas para as velhices são planejadas e materializadas nos serviços de saúde, a partir da atuação dos profissionais junto aos usuários.

Foi preciso trazer, ainda, para esta discussão, aspectos conceituais relativos à formulação, execução e controle das políticas públicas, entendendo-se esses momentos, que compõem o chamado ciclo de uma política, para além de uma perspectiva linear. A intenção se deu, apoiada em Ferreira, Alencar, e Pereira (2012), em vislumbrar as ações voltadas para as velhices e para a Aids superando uma visão meramente estratégica e administrativa dividida em etapas. Dessa forma, norteada por um olhar interdisciplinar, e não centralizado apenas na operacionalização das etapas, voltamos para outras questões a serem quantificadas, qualificadas, desdobradas e complementadas, mais concernentes à cadeia de agentes envolvidos nos processos, considerando-se que estes estão em contínua interação, ou ao menos deveriam estar. 
Uma leitura dessa constatação sob o aporte da integralidade na saúde revela a premência de transgredir as políticas setoriais, com recusa em objetivar e recortar os sujeitos sobre os quais a política incide, e que, dessa forma, ampliar-se o horizonte de problemas a serem trabalhados. Na realidade, esses problemas são pensados de forma reducionista, sem levar em conta os contextos culturais e as diversas formas de dominação que conferem especificidades ao adoecimento das pessoas, em que se priorizam aspectos desse adoecimento produzidos pelas exclusividades biológicas, em detrimento daquelas de cunho cultural, social e econômica (Mattos, 2001).

No lastro dessas compreensões, Bowe (citado em Giron, 2012), relata que a produção de uma política pública sofre influência de três contextos. O contexto da influência é o momento em que as políticas públicas são gestadas e os discursos políticos são construídos; o contexto da produção que remete à elaboração dos textos políticos e legais oficiais; o contexto da prática, em que se localizam os interesses desta pesquisa, responde pelo momento em que a proposta política está sujeita à interpretação dos diferentes atores envolvidos no processo, podendo sofrer modificações a serem recriadas, tendo em vista sua aplicabilidade.

A PNSPI, alinhada aos princípios do SUS, firmando-se em conceitos ampliados de saúde da pessoa idosa, reconhece-a como interação entre saúde física, mental, independência financeira, capacidade funcional e suporte social, extrapolando-se o controle e a prevenção de agravos de doenças crônicas. Suas diretrizes suscitam elementos que conduzem a um cenário de abrangência da heterogeneidade do segmento idoso, pautadas nos moldes de linhas de cuidado, com foco no usuário, baseado nos direitos, necessidades, preferências e habilidades dos idosos. Mas se trata do contexto da produção, do texto legal concebido.

$\mathrm{O}$ contexto da prática no tocante à saúde do idoso, por sua vez, revela as subjetividades dos sujeitos implicados nesse campo, gestores e profissionais, concretizadas nas decodificações que estes fazem dessas diretrizes ou mesmo no desconhecimento acerca destas, requisitos que repercutem no planejamento e execução das ações designadas à pessoas idosa, não apenas relativo ao conteúdo dessas ações, mas às escolhas feitas para se chegar a esses conteúdos, denunciando concepções, percepções, visões, conhecimentos, uso de ferramentas, recursos disponíveis, realçando aspectos objetivos e subjetivos. 
Dentro desses direcionamentos teóricos, pude constatar por meio dos discursos dos interlocutores do estudo que atuam na FMS, tal como retrata a fala abaixo, que o planejamento das ações direcionadas para o idoso se dá em dissonância com os pressupostos da PNSPI, tendo em vista a correlação incipiente ou praticamente nula entre o que é priorizado a ser desenvolvido na área da saúde do idoso e o que preconizam as diretrizes da mencionada política, principalmente no que remete à integralidade da atenção, ações intersetoriais e estímulo à participação, visto que o planejamento aqui abordado acessa a problemática que permeia o envelhecimento, não considerando a multicausalidade que faz parte dos fenômenos humanos e, portanto, há a necessidade de, nas palavras de Ferreira, Alencar, e Pereira (2012), superar a visão dos problemas de "cima para baixo" (grifos dos autores), considerando no fluxo do planejamento aqueles que estão mais próximos das ações resultantes das políticas:

"Na verdade, essas atividades elas foram, quando chega janeiro, dezembro, você faz um relatório do que foi feito no ano passado e, aí em cima desse relatório, já foi planejado isso aqui, junto com as diretorias, as três regionais. É planejado junto com elas." (Jade)

Trata-se, segundo Queiroz (2012), de um planejamento normativo, suportado em métodos essencialmente quantitativos e, por esta razão, configura-se como superficial e incompleto, por ser reflexo de um diagnóstico estático e distante da realidade e restrito a um grupo pequeno de pessoas, no sentido de representatividade dos aspectos trabalhados, vislumbrando a velhice como um problema matemático, com soluções únicas e inquestionáveis, e não como um problema social, no qual não cabem soluções únicas e nem aceitas por todos, requerendo sólida fundamentação estratégica para a percepção de uma situação real.

Em uma fundamentação estratégica, a subjetividade humana é incorporada no processo de planejamento, incentivando a participação dos atores envolvidos na explicação e no entendimento das realidades, estas dinâmicas e complexas, aumentando a compreensão do problema, o que ordena imperiosamente incluir a intersetorialidade e a cooperação entre as organizações governamentais e não governamentais, além de entender que o resultado de uma política pública não depende apenas do desenho do programa em si, mas também das circunstâncias sociais que ele opera, que não são totalmente previsíveis e controláveis (Queiroz, 2012). 
Para tanto, se faz necessária uma desconstrução da ideia que dicotomiza o processo de formulação das políticas públicas, atribuindo a espaços distintos as tarefas de planejamento e de execução das ações. Ideia produtora do distanciamento entre os sujeitos e geradora de ilhas de atuação, vislumbrando o planejamento apenas como um produto técnico e não como um processo, sendo que, assevera Oliveira (2006), um dos motivos que levam a falhas nos resultados das políticas públicas é justamente a dissociação entre elaboração e implementação no processo de planejamento.

Esse pensamento fragmentado que leva a ações igualmente fragmentadas impera entre os profissionais que desempenham suas atividades laborais na FMS, implícito nas falas destes, imprimindo um panorama destoante daquele apregoado pelos princípios do SUS. Este orienta a construção e implementação das políticas públicas pela ótica da integralidade da atenção e intersetorialidade das ações, devendo estes nortes teóricos agregarem, de acordo com Mattos (2001), uma recusa ao reducionismo, à objetivação dos sujeitos e uma abertura para o diálogo.

"Participa assim, a gente só apoia, quem executa mesmo são as unidades básicas de saúde gerenciadas pelas diretorias; a gente só faz apoiar, né?; é, repassar algumas coisa do Ministério da saúde, alguma Portaria recente, a gente repassa, mas a gente trabalha o tempo todo, a, a, como é que se diz?, o gerenciamento mesmo, a responsabilidade, é das diretorias, é descentralizado, a gente só faz apoiar, a gente é só pra poder ficar, né?, a gente fica só relembrando, né?, as diretrizes da política. (Jade)

\section{[...] aqui é mais gestão, a gente passa para a ponta. (Diamante)}

Essa transferência de responsabilidades, a mencionada, nos discursos das interlocutoras, 'descentralização', termo que uma delas utiliza para justificar os encargos da execução das ações repassados aos profissionais da ponta assistencial, aqueles que ocupam os espaços dos serviços de saúde, merece uma reflexão. Em primeiro plano, essas ações são pensadas a partir de aspectos meramente quantitativos, dentro de um formato verticalizado de fazer política. Além disso, mesmo esse repasse, que por si só já é repleto de lacunas, parece se dar no limbo, haja vista não ser ancorado em conversas, alinhamentos e compreensões, sustentando, dessa maneira, práticas fracionadas e sem interface com as realidades dos atores implicados. 
Uma desconexão que incute interrupções significativas no decorrer da implantação das ações, quando, segundo Ferreira, Alencar, e Pereira (2012), diretivas administrativas se transformam em diretivas práticas e a falta de visão sobre os problemas potenciais que podem surgir durante a execução de uma política, favorecida por essa segregação clara entre formuladores e implementadores, inevitavelmente, resulta em paralisações, descontinuidades de ações e prejuízos.

A política em ação, certifica Jesus (2014), não pode ser definida no âmbito da macropolítica; envolve a micropolítica, lugar dos sujeitos/atores diretamente ligados com a prática, considerando-se as relações que são estabelecidas entre os sujeitos/atores, sejam estes indivíduos ou instituições. É nesse espaço da micropolítica que, nas palavras de Raeder (2014), intenções são convertidas em ações, e se percebe a importância dos efeitos retroalimentadores da implementação sobre a formulação de políticas, sedimentadores de consensos quanto às metas e objetivos entre aqueles que executam a política e os que a formulam.

É preciso olhar para os agentes implementadores das políticas públicas que respondem por aqueles que trabalham diretamente com os usuários dos serviços públicos e que nos deixam em evidência que, apesar das normas comunitárias e administrativas, esses agentes conseguem ter autonomia para decidir como aplicá-las e inseri-las nas práticas; dentro desse contexto é que as políticas públicas podem ser alteradas e reconstruídas (Ferreira, Alencar, \& Pereira, 2012).

No que diz respeito às ações voltadas para a atenção à saúde do idoso, encontramos um cenário de planejamento restrito a uma sala, do qual um grupo limitado de pessoas participam, limitações que extrapolam o cunho quantitativo, uma vez que são sustentadas em um distanciamento das questões que cercam o pensar e o fazer na atenção à saúde do idoso. Em outras palavras, não toma assento nesse planejamento a própria PNSPI, como todas as suas diretrizes norteadoras, em que conferimos destaque à integralidade e intersetorialidade, as realidades dos serviços de saúde, que nos permitem captar os potenciais obstáculos em termos de estrutura, recursos disponíveis e preparo dos profissionais para materialização das ações e agir de maneira proativa, como também as necessidades e expectativas da pessoa idosa, pois os segmentos com potencial para representar esses sujeitos não são trazidos e nem se colocam à cena para uma construção coletiva. 
Os momentos de aproximação entre esses autores significativos para o delineamento de ações exitosas na área de atenção à saúde do idoso se dá de forma muito incipiente e pontual, apenas na semana trabalhada em alusão à pessoa idosa, e o discurso das coordenações municipais põe isso em evidência, concentrando os feitos destinados a essa população em um período, além de aceder um grupo tão heterogêneo por trajetórias tortuosas de atuações, destoante muitas vezes de suas experiências e prioridades em marcos de cuidado.

"O Conselho sempre convida a gente, porque tem um representante aqui do município, mas eu não sei, por enquanto as representantes elas trabalham lá no, no, no Centro de Convivência [...]” (Jade)

"Mas, assim, na Semana do Idoso, eles mandam o convite, a gente participa, quando tem missa, o Conselho sempre convida a gente [...] " (Jade)

As ações são confinadas em espaços desmembrados, concorrendo para moldar um panorama insuficiente diante da complexidade que cerca a velhice, complexidade esta expressa na sua multidimensionalidade. Como caminhos consequentes, o idoso é recortado, dando-se ênfase a algumas especificidades dessa fase da vida, circunscritas à dimensão biológica, de maneira que ganham visibilidade aspectos remetentes à atividade física; afinal, é preciso manter o idoso "ativo" (grifos nossos") e às tão conhecidas e reconhecidas diabetes e hipertensão, atores principais no palco de atenção à saúde do idoso:

"[..] já tive com o pessoal da, que tem a questão da atividade física, já tive com eles $[. .] ”.($ Jade)

"Agora mesmo a gente está planejando um trabalho lá com a nutricionista, assim, que lá no Centro de Convivência do Lineu tem muitos casos de diabetes, nessa faixa etária, né?, e hipertensão; então, a gente vai fazer uma oficina lá, de mostrar pra ele, junto com o SESI, aí eles vão lá fazer, mostrar, né?, como se faz uma alimentação saudável e ao mesmo tempo degustar para saber que essa alimentação também tem sabor; como a gente faz essa alimentação de uma forma que ela não perca seu sabor e seja saudável." (Jade) 
Em que pese a importância dessas ações, diante de algumas realidades que agregam a heterogeneidade do envelhecer, elas não conformam as necessidades de todos os idosos e, portanto, não podem ser tomadas como regras. Segundo Mattos (2001), nas políticas públicas há de existir a busca de uma visão mais abrangente daqueles que são alvos das políticas de saúde, rejeitando um recorte do problema que o reduza a uma ou algumas de suas dimensões, desconsiderando as demais, haja vista as respostas aos problemas de saúde exigirem um olhar às suas diversas dimensões. É um dos sentidos que a integralidade assume na saúde, como princípio orientador de organização das políticas públicas.

Uma integralidade que não guia o planejamento das ações e, consequentemente, não se faz presente na organização das práticas direcionadas aos idosos nos serviços de saúde, conformando ações igualmente distantes das possibilidades de apreensão dos cenários de experiências dos indivíduos idosos, limitando mais uma vez o agir diante das pessoas idosa, algo perceptível nas falas dos profissionais de saúde, quando ganham destaque novamente as denominadas doenças crônicas não transmissíveis, revelando uma visão da velhice pela lente das alterações físicas que concorrem para essas doenças consideradas próprias do ser que envelhece: "Hoje nós temos os grupos da terceira idade, que nós trabalhamos,
principalmente a questão é do hipertenso, do diabético [...]" (Quartzo)

“[...] eles são atendidos aqui na unidade, mais no grupo do hipertenso $e$ diabético [...]” (Pérola)

"[...] no dia do hiperdia, que é um dia que eu reúno os idosos, assim, os hipertensos e diabéticos [...]" (Ametista)

A Estratégia Saúde da Família (ESF), pela proximidade com a comunidade a ser cuidada, em sua essência abriga possibilidades de um melhor entendimento das necessidades de saúde das pessoas, contribuindo para uma ruptura da fragmentadora verticalização das ações e abrindo caminhos para a horizontalização, um pensar das práticas a partir do horizonte da população. Para Mattos (2001), diante dessas novas questões, outras tensões se colocam; afinal, é preciso dar conta de uma demanda espontânea por consulta que chega às unidades de saúde e a uma demanda programada, com a finalidade de fazer das ações e serviços de saúde um produtor de impactos positivos sobre a saúde das pessoas. 
Nesse contexto, ganha enorme destaque a epidemiologia como disciplina guardachuva, capaz de apreender quais seriam as reais necessidades de saúde da população, orientando as equipes na definição das atividades a serem programadas, por faixas etárias, priorizando algumas doenças a agravos frequentes e passíveis de ações preventivas e de controle. A grande lacuna aqui gerada é que a epidemiologia, apesar de oferecer ótimas ferramentas para alcançar as percepções das necessidades de serviços de saúde de uma população, não se configura como a única forma de caracterizar tais necessidades, isso porque algumas destas simplesmente não podem ser concebidas pela dimensão epidemiológica, existindo ações que se justificam independentemente do impacto epidemiológico que porventura produzam (Mattos, 2001).

Nesse panorama, desenha-se um cuidado fragmentado ao idoso nos serviços de saúde, a partir de um recorte da pessoa que envelhece. Além disso, o modelo assistencial vigente, que norteia a prática dos profissionais de saúde, contribui para uma homogeneidade nas ações, não vislumbrando as especificidades e particularidades que permeiam a atenção à saúde do idoso. O caminho é a segmentação da pessoa em pedaços a serem "cuidados" por especialistas que perdem de vista o ser em sua integralidade, tal como evidencia o discurso de uma das interlocutoras do estudo:

"O atendimento segue a mesma rotina dos demais pacientes. Só os encaminhamentos são diferentes, geralmente eles fazem, fazem acompanhamento com o cardiologista ou com o endócrino, ou com com o geriatra; tem pacientes que fazem acompanhamento com o geriatra também, mas assim, a gente não tem um, um, um plano terapêutico só, diferente, referenciado ao idoso não." (Rubi)

Assim, constatamos, no planejamento e na execução das ações direcionadas para os idosos, uma sobreposição do saber técnico em cima do saber dos atores locais, tendo em vista que há um objetivação da realidade, pautada em números e índices de adoecimento e mortalidade, por vezes produzidos em um contexto nacional, para acessá-la em termos de atuações dos profissionais de saúde, independentemente da posição por estes ocupadas na linha do cuidado à pessoa idosa; a referência é a todos, àqueles considerados gestores e àqueles considerados executores de ações. A nosso ver, são todos profissionais de saúde e aqui entendemos a premência em desconstruir tais nichos segregadores que apenas servem para alimentar cada vez mais a ideia de pessoas e instituições que pensam uma problemática e de como resolvê-la e as que fazem, executam essas soluções. 
Torna-se relevante a interação entre esses dois tipos de saberes no processo de construção, implementação e controle de uma política pública, nos alertam Ferreira, Alencar, e Pereira (2012) e Teixeira (2002). Para esses autores, o saber técnico está pautado na objetividade, determinismo e rigorosidade das ciências, em que especialistas assumem o papel de atores principais nas decisões de Estado em relação à sociedade, decisões tomadas com base apenas em padrões racionais, sem levar em consideração as necessidades e heterogeneidades da sociedade. O saber dos atores locais, por sua vez, assim como suas experiências, estilos de vida, percepções e valores, contextos, tradições e valores influenciam na compreensão da realidade social dos atores, podendo esta ser utilizada para identificar os problemas, as necessidades e as aspirações que permeiam uma política pública. De acordo com Bosi (2003), a história que se apoia unicamente em documentos oficiais, não pode dar conta das paixões individuais que se escondem atrás dos episódios. A fala de quem vive a realidade, longe da unilateralidade para a qual tendem certas instituições, faz intervir pontos de vista contraditórios, pelo menos distintos entre eles, e aí se encontra a maior riqueza.

\section{Considerações Finais}

As ações de saúde voltadas para as pessoas idosas são planejadas e executadas de forma fragmentada, com espaços distintos para pensar e para agir, não existindo canais de diálogo entre esses locais, contribuindo, dessa forma, para atuações distantes das realidades que se deseja alcançar. Além disso, essa ações são formuladas e implementadas a partir de concepções do ser idoso, muito atreladas a uma faixa etária, não visualizando as velhices em sua heterogeneidade. Vislumbra-se uma priorização do saber técnico sobre o saber dos atores locais.

Longe de querer engendrar uma hierarquia entre os saberes abordados, a pretensão recai em mostrar a importância de uma relação dialógica entre esses dois universos de significação e compreender que não se pode desconsiderar a importância do saber técnico, ilustrado pela realização de pesquisas que fomentam com informações, indicadores e modelos quantitativos da gestão de políticas públicas. É preciso, no entanto, compreender os limites desse saber, uma vez que não pode alcançar todos os meandros que conformam a realidade social. Além disso, todo o saber técnico é provisório e depende do contexto histórico, no qual os fenômenos são observados e interpretados. 
Alguns ingredientes precisam ser incorporados a esse panorama, a fim de alcançar a complexidade dos contextos que chegam até os serviços de saúde. Referimo-nos à necessidade de um planejamento e atendimento baseados na integralidade, no entendimento do ser cuidado sob a ótica da multidimensionalidade e heterogeneidade, o que requer extrapolar a objetividade do saber técnico que normatiza as ações e encobre as subjetividades, estas relevantes para ampliar o nosso olhar em direção às necessidades e demandas que se colocam nos encontros dos usuários idosos com os profissionais de saúde. Essas questões prescindem a contemplação do processo de construção, implementação e controle de uma política pública.

\section{Referências}

Alencar, M. S. S., \& Carvalho, C. M. R. G. (2009). O envelhecimento pela ótica conceitual, sociodemográfica e político-educacional: ênfase na experiência piauiense. Botucatu, SP: Interface: Comunicação, Saúde e Educação, 13(29). Recuperado em 15 agosto, 2011, de: www.scielo.br/scielo.php?pid=S1414-32832009000200015...sci...

Andrade, H. A. S., Silva, S. K., \& Santos, M. I. P. O. (2010). Aids em Idosos: vivências dos doentes. Rio de Janeiro, RJ: Escola Anna Nery, 14(4), 1-15. Recuperado em 19 março, 2013, de: http// www.google.com.br/\#q=Aids+em+Idosos\%3A+viv\%C3\%AAncias+dos+doentes.

Berlezi, E. M., Eickhoff, H. M., Oliveira, K. R. de, Dallepiane, L. B., Perlini, N. M. O. G., Mafalda, A., \& Bueno, C. (2011). Programa de atenção ao idoso: relato de um modelo assistencial. Florianópolis (SC): Texto e Contexto-Enfermagem, 20(2), 368-375. Recuperado em 02 fevereiro, 2013, http://www.scielo.br/pdf/tce/v20n2/a16v20n2.pdf.

Bosi, E. (2003). O tempo (vivido) vivo da memória: ensaios de psicologia social. ( $2^{\mathrm{a}}$ ed.). São Paulo, SP: Ateliê Editorial.

Camacho, A. C. L. F., \& Coelho, M. J. (2010). Políticas públicas para a saúde do idoso: revisão sistemática. Brasília, DF: Revista Brasileira de Enfermagem, 63(2), 279-284. Recuperado em 12 fevereiro, 2013, de: http://dx.doi.org/10.1590/S0034-71672010000200017.

Ciosak, S. I., Braz, E., Costa, M. F. B. N. A., Nakano, N. G. R., Rodrigues, J., Alencar, R. A., Rocha, A. C. A. L. da. (2011). Senescência e Senilidade: novo paradigma na atenção básica de saúde. São Paulo, SP: Revista da Escola de Enfermagem da USP, 45(2), 2011. Recuperado em 2 fevereiro, 2013, de: http://www.scielo.br/pdf/reeusp/v45nspe2/22.pdf.

Debert, G. (2011). Metamorfoses da Velhice. In: Botelho, A., \& Schwarcz, L. M. (Orgs.). Agenda Brasileira: temas de uma sociedade em mudança. São Paulo, SP: Companhia das Letras.

Elias, N. (2001). A solidão dos moribundos: seguido de envelhecer e morrer. Plínio Dentzien, Trad. Rio de Janeiro, RJ: Jorge Zahar. 
Ferreira, P. A., Alencar, E., \& Pereira, J. R. (2012). Revisitando o modelo processual de análise de políticas públicas a partir das relações entre Estado e Sociedade. In: VI ENAPEGS - Eixo temático 2: Gestão social, políticas públicas e território. São Paulo, 2012. Recuperado em 15 dezembro, 2014, de: http://anaisenapegs.com.br/2012/dmdocuments/186.pdf.

Freitas, E. V., Neri, A. L., Cançado, F. A X., Doll, J., \& Gorzoni, M. L. (2006). Tratado de geriatria e gerontologia, 02-12. ( $2^{\mathrm{a}}$ ed.). Rio de Janeiro, RJ: Guanabara Koogan.

Giron, G. R. (2012). A influência da política, do planejamento e da gestão educacional na formação social do indivíduo. In: IX ANPED SUL - Seminário de Pesquisa em Educação da Região Sul. Caxias do Sul, RS, 2012. Recuperado em 15 dezembro, 2014, de: http://www.ucs.br/etc/conferencias/index.php/anpedsul/9anpedsul/paper/viewFile/409/109.

IBGE. (2015). Instituto Brasileiro de Geografia e Estatística. Mudanças demográficas no Brasil no início do século XXI - subsídios para as projeções das populações. Rio de Janeiro, RJ. Recuperado em 24 março, 2015, de: http://biblioteca.ibge.gov.br/visualizacao/livros/liv93322.pdf.

Laroque M. F., Affeldt, Â. B., Cardoso, D. H., Souza, G. L. de, Santana, M. da G., \& Lange, C. (2011). Sexualidade do idoso: comportamento para a prevenção de DST/AIDS. Porto Alegre, RS: Rev. Gaúcha Enferm., 32(4). Recuperado em 01 fevereiro, 2015, de: http://dx.doi.org/10.1590/S1983-14472011000400019.

Jesus, R. B. (2014). Políticas Públicas e o Ciclo de Políticas: uma análise da política de Mato Grosso. São Paulo, SP: Revista Científica Eletrônica de Pedagogia, 24 (Ano XII). Recuperado em 15 dezembro, 2014, de: http://faef.revista.inf.br/imagens_arquivos/arquivos_destaque/ uAn890zrR7yA164_2014-11-7-18-43-38.pdf.

Lima, C. A., \& Tocantins, F. R. (2009). Necessidades de saúde do idoso: perspectivas para a enfermagem. Brasília, DF: Revista Brasileira de Enfermagem, 62(3), 367-373. Recuperado em 02 fevereiro, 2013, de: http://dx.doi.org/10.1590/S0034-71672009000300006.

Lima, T. J. V. de, Arcieri, R. M., Garbin, C. A. S., \& Moimaz, S. A. das S. (2010). Humanização na atenção à saúde do idoso. São Paulo, SP: Revista Saúde e Sociedade, 19(4), 866-877. Recuperado em 1 junho, 2014, de: http://www.scielo.br/scielo.php?script=sci_arttext\&pid=S0104-12902010000400013.

Marrano, M. N. O., \& Simões, M. V. (2006). O significado de envelhecer no discurso dos idosos descendentes de imigrantes italianos. São Paulo, SP: Unimep Biblioteca Digital. Recuperado em 01 junho, 2014, https://www.unimep.br/phpg/bibdig/aluno/visualiza.php?cod=32.

Mattos, R. A. (2001). Os sentidos da integralidade: algumas reflexões acerca dos valores que merecem ser defendidos. In: Mattos, R. A., \& Pinheiro, R. Os sentidos da Integralidade na atenção e no cuidado à saúde, 39-64. Rio de Janeiro, RJ: ABRASCO.

Minayo, M. C. S., \& Gomes, S. F. D. R. (2012). Pesquisa social: teoria método e criatividade. (32 ed.). Petrópolis, RJ: Vozes.

Mucida, A. (2006). O sujeito não envelhece: psicanálise e velhice. (2a ed.). Belo Horizonte, MG: Autêntica.

Oliveira, J. A. P. (2006). Desafios do planejamento em políticas públicas: diferentes visões e práticas. Rio de Janeiro, RJ: Revista de Administração Pública. Recuperado em 15 dezembro, 2014, de: http://www.scielo.br/pdf/rap/v40n2/v40n2a06. 
Oliveira, J. C. A., \& Tavares, D. M. S. (2010). Atenção ao idoso na estratégia de Saúde da família: atuação do enfermeiro. São Paulo, SP: Revista da Escola de Enfermagem da USP, 44(3), 774-781. Recuperado em 12 fevereiro, 2013, de: http://www.scielo.br/pdf/reeusp/v44n3/32.pdf.

Omelczuk, F., \& Monteiro, G. G. (2014). Imagens de uma nova velhice: considerações a partir do filme $E$ se vivêssemos todos juntos? São Paulo, SP: PUC-SP: Revista Kairós Gerontologia, 17(4), 245-259. Recuperado em 01 de dezembro, 2014, de: file:///C:/Users/Dados/Downloads/23877-61753-1-SM\%20(1).pdf.

OMS. (2005). ORGANIZAÇÃO MUNDIAL DE SAÚDE. Envelhecimento ativo: uma política de saúde. Suzana Gontijo, Trad. Brasília, DF: Organização Pan-Americana de Saúde, 2005. Recuperado em 15 dezembro, 2015, de: http://bvsms.saude.gov.br/bvs/publicacoes/envelhecimento_ativo.pdf.

Queiroz, R. B. (2012). Formação e Gestão de Políticas Públicas. Curitiba, PR: Intersaberes.

Raeder, S. (2014). Ciclo de Políticas: uma abordagem integrada nos modelos para análise de políticas públicas. In: Perspectiva em Políticas Públicas, VIII(3). Belo Horizonte, MG.

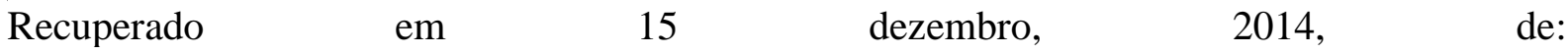
http://revistappp.uemg.br/pdf/ppp13/ciclo_de_politicas.pdf.

Schimidt, T. C. G. S., \& Silva, M. J. P. (2012). Percepção e compreensão de profissionais e graduandos de saúde sobre o idoso e o envelhecimento humano. São Paulo, SP: Revista Escola de Enfermagem da USP, 46(3), 612-617. Recuperado em 12 fevereiro, 2013, de: http://www.scielo.br.

Silva, J. V. (2009). Saúde do idoso e a enfermagem: processo de envelhecimento sob múltiplos aspectos. São Paulo, SP: Iátria.

Spink, M. J. P., \& Medrado, B. (2000). Produção de sentidos no cotidiano: uma abordagem teórico-metodológica para análise das práticas discursivas. In: Spink, M. J. P. (Org.). Práticas discursivas e produção de sentidos no cotidiano, 41-61. (2 ${ }^{\mathrm{a}}$ ed.). São Paulo, SP: Cortez.

Teixeira, E. C. (2002). O papel das políticas públicas no desenvolvimento local e na transformação da realidade. In: $A A T R-B A$, Associação dos Advogados dos Trabalhadores Rurais da Bahia, Bahia, Brasil. Recuperado em 15 dezembro, 2014, de: http://www.dhnet.org.br/dados/cursos/aatr2/a_pdf/03_aatr_pp_papel.pdf.

Recebido em 10/11/2015

Aceito em 30/01/2016 
Susane Fátima Ferreira de Castro - Enfermeira, docente e pesquisadora filiada à Faculdade de Tecnologia e Educação Superior Profissional (FATESP). Doutora e Mestre em Políticas Públicas, Universidade Federal do Piauí, Brasil (2015). Enfermeira do Hospital de Urgências Dr. Zenon Rocha, Brasil.

E-mail: susaneffcastro@ hotmail.com

Francisco Oliveira Barros Júnior - Doutor e Mestre em Ciências Sociais, PUC-SP. Cientista Social, PUC-SP. Professor titular da Universidade Federal do Piauí (UFPI), atuando em temas como: Bioética, Síndrome de Imunoficiência Adquirida, Envelhecimento, Educação Gerontológica, Universidade Aberta para a Terceira Idade, Saúde Pública, Políticas Públicas. E-mail: barrosjr@ufpi.edu.br 